\title{
The Need for a Content and Language Integrated Learning (CLIL) Approach in Kurdistan Education System
}

\author{
Aree Ghazi Hussain \\ MA in ELT \\ Cihan University - Erbil
}

\begin{abstract}
Content and language integrated learning (CLIL) approach has become a much debated feature of the education system in recent years. The study reported here examines the role of CLIL within the context of the Kurdistan Educational System. In particular, it investigates CLIL implementation in Kurdistan's schools and its impact on the acquisition of the English language, contents of main subjects at the individual level, students and teachers, and the whole educational system. The study does not examine the impact of CLIL within the Kurdish education system, but a possible role for it. In order to do this, it first reviews the existing theoretical viewpoints on CLIL and its significance in language learning through the study of content of other subjects. A framework is then developed to describe the current situation of the Kurdistan Educational System and review CLIL in a different context. Data is obtained mainly through questionnaires to teachers and students in the Kurdistan Educational System and semi-structured interviews with two Spanish students who had experience in CLIL. All collected perceptions are analysed and implications for the usefulness of CLIL for Kurdistan Education System, teachers' and students' perspective on implementing CLIL in Kurdistan's school and how CLIL be implemented in Kurdistan. Data from the study suggests that studying the content of some of the main subjects in Kurdistan's schools provides more opportunity to expand intellectual horizons of students while improving their English language skills and knowledge. Owing to these reasons, integrating learning language and content from early age in schools will impact the entire education and higher education systems in Kurdistan. This is the first study to investigate the role of CLIL in the Kurdish context and further longitudinal studies are required to improve our understanding of the implications of the wider introduction, role, and advantages of implementing CLIL in Kurdistan and how to incorporate CLIL into Kurdish education policy.
\end{abstract}

\section{BACKGROUND}

Learning languages is a potent instrument for developing education and entire culture. Kurdistan is seeking openness to the world by raising its educational level, along with its political and economic systems, in

\author{
Naeema Hann \\ $\mathrm{PhD}$ in ELT \\ Leeds Beckett University
}

order to ensure the stability and prosperity of its future generations. To promote this goal, there is considerable interest in learning English in today's Kurdistan.

What is the content and language integrated learning (CLIL) approach? For the purpose of this study, CLIL is defined as the integration between learning English language and subject content. CLIL is one of the second language acquisition approaches which formulated in Europe in early 1990s, based on combining the acquisition of an additional language with subject matter to learn both new material and the target language at the same time (Harrop, 2012; Marsh, 2000).

However, the actual practice of CLIL has a much longer history that dates back 5000 years to Mesopotamia, today's Iraq (Mehisto et al., 2008; Marsh, 2012). The Sumerian instructors combined instruction to the Akkadians in subjects such as theology, botany, and zoology in order to learn their local language (Mehisto et al., 2008, p. 9). Also another example of the history of practicing CLIL is Latin in the Middle Ages, when it became the primary language of studying law, medicine, mathematics, theology, and philosophy in Europe's early universities (ibid).

Today, CLIL is one of the established second language acquisition approaches and has its own area of research and practice in the study of language learning and teaching process: "content and language integrated learning (CLIL) is a dual-focused educational approach in which an additional language is used for the learning and teaching of both content and language" (Coyle et al., 2010: p. 1). By including in-depth content, CLIL supplies additional motivation for students to learn the subject matter through understanding the target language. 


\section{PURPOSES OF THE STUDY}

The purposes of this study are to:

1- Describe the role of implementing CLIL approach in the Kurdistan education system;

2-Investigate the nature of teachers' and students' perspective on studying subjects in English in Kurdistan schools;

3-Analyse the impact of learning English on Kurdistan learners' development in their subject knowledge by examining whether and how it helps to improve teaching and learning quality when they are studying science subjects in their first language in schools. However, English is the language of their higher education system, as well as the international language of science and technology;

4- Make some suggestions and recommendations as to how CLIL in Kurdistan's educational system might be implemented, which subjects could be taught in English and what the government, universities, schools, parents, and teachers could do to facilitate both subject matter and language learning.

\section{REASONS FOR THE STUDY:}

Several factors in the current situation of Kurdistan's education system sparked off the idea to do this study. Firstly, there is a gap between the lower-level and the higher education systems in terms of language of teaching. Kurdistan's education policy permits students to begin studying all subjects in their first language; however, English is the primary language of higher education system, especially in science subjects in all the universities (Sharif, 2013). Therefore, students are very likely to face problems with the language use when they begin attending university and have to spend time to learn a new language in order to understand the content of their lessons. This language gap and the efforts required to overcome it may have a negative impact on the entire education process in terms of quality and pace of development.

A second reason for carrying out this study is that CLIL can offer better quality teaching in Kurdistan's education system. Why? As noted above, while the main language of higher education system for the science subjects is English, when a newly-trained teacher arrives at a school, he or she has to use the students' first language to teach the subject matter. On the other hand, when the students are attending the universities to study mathematics, physics, chemistry, biology, medicine, and engineering they have to translate from their first languages and learn in English the meanings of all the terms and terminologies that they learned in school. In both cases, teachers and students may feel deeply confused at the beginning of the process.
Thirdly, the CLIL approach can help solve the problem of providing enough professional teachers in Kurdistan's education system to teach those subjects to groups such as Turkmen, Assyrians, and Arabs in Kurdistan schools, because all the teachers will be ready to use English to teach. Compared to the majority language of Kurdish and the languages of minority ethnic groups such as Turkmen, Assyrians, and Arabs, English could be seen as a neutral language in the Kurdish context.

Finally, implementing CLIL permits teachers to employ different types of assessment methods rather than doing only exams, as they do now. The teaching process in Kurdistan's education system still focuses on only one textbook in a class, at the end of which the students write exams. In CLIL classes, students have more options to find resources and materials outside the classroom because they are able to read and understand the target language of English. In a country such as Kurdistan with multiple languages, it is difficult to provide sufficient high-quality resources such as books and articles in all the required languages when the global research centres and universities are continually presenting new findings. By using CLIL and English, teachers and students would have access to resources that permit different types of assessment methods, such as writing assignments, case studies, presentations, and longer research projects.

\section{LIMITATIONS:}

It is clear the work on implementing a new approach in an education system that has different types of schools using different language will have serious challenges. Kurdistan has six types of schools; some use Kurdish is the main teaching language, while others include English, Turkmen, Arabic, Assyrian, NeoAramaic, and Chaldean Neo-Aramaic, depending on the makeup of the community where a particular school is located. Given its scope, this study will be unable to consider all the essential issues in implementing CLIL, such as how to deal with large class size, how to develop teacher and staff ability to work in CLIL classes, who will write and choose the materials to be used in CLIL classes, and how the use of technology will influence the teaching and learning in CLIL classes.

This study will examine areas such as the impact of how a CLIL approach may lead students to more intercultural awareness, motivation, and autonomy in learning process. However, each of those aspects needs more research to show possible positive and negative impacts in the Kurdish context. Instead, this study focuses on which subjects, such as science and 
JUHD / Vol. 2, No. 4, December 2016: pp 410-417

e-ISSN: 2411-7757, p-ISSN 2411-7765

humanities topics, can be taught using CLIL classes in Kurdistan education system. However, the results and conclusion will be a recommendation to apply this approach, because it can be modified along with evolutions in the Kurdish government's education policy and strategy for the entire education system.

\section{WHAT IS CLIL?}

A large and growing body of literature has investigated the role of learning English language in the context of educational development. In countries that have more than one language, and in which English is not the main language, the content and language integrated learning (CLIL) approach can shift English from being a library language to being a skill that can enhance the students' communicative abilities in the learning process.

In CLIL classes, students can learn the content and gain necessary knowledge of the subjects being taught while they are using the English language. Coyle (2007) defines CLIL as "bilingual education", which means that the teaching process involves the use of two languages that students apply to learn the content of the subjects they are being taught and to improve their use of English. Consequently, Gajo (2007) used the term, "umbrella", to describe this approach in a bilingual education system in which CLIL includes a range of bilingual approaches and strategies in teaching (cited in Dalton-Puffer et al., 2010). Therefore, implementing CLIL can facilitate the learners' need to improve the language they have to learn and understand what they have to learn through learning a language. Moreover, Dalma (2013) considered CLIL to be a constructivist approach to learning a target language because it focuses on transferring information from teacher to learner while the learner has a high degree of participation in the process.

Mehisto et al. (2008) identified CLIL as a teaching and learning tool that focuses on content and language; the core of this approach is integration, which has a dual focus. The first focus is the language learning process, which involves learning about subjects such as mathematics, science, history and geography. The second focus emphasises the content in the subject matter that is used for the purpose of learning a language; that is, students have to learn some vocabulary and terminology to understand the content.

However, Deller and Price (2007) highlighted the essential difference between using language to teach language classes and using it to teach content classes. "In the language class the four skills (reading, listening, speaking and writing) are part of the end product and are also a tool for introducing new language and practicing and checking linguistic knowledge. In the content classroom the four skills are a means of learning new information and displaying an understanding of the subjects being taught" (Deller and Price, 2007: 7).

In terms of the role of language in CLIL, Llinares et al. (2012) stated that at least two languages are used in teaching CLIL classes: the national or majority language and English. However, there are multilingual contexts where CLIL classes have to use two additional languages (for example in the case of the Basque Country, Spanish and Basque languages are used with English and in the Kurdistan context, more than two additional languages such as Kurdish, Arabic and Turkish with English, can be used).

A successful CLIL course consists of four elements, which are called the "4Cs of CLIL". The first C is the content, which is the specific subject that is to be taught. The second $\mathrm{C}$ is communication, which refers to using the target language that is used to teach the subject content. The third $\mathrm{C}$ is cognition, which is used to develop the students' thinking ability so they can understand the subject using the target language. The fourth $\mathrm{C}$ is culture, which means that learning a foreign language will deepen the learners' awareness when CLIL gives them an opportunity to learn from different cultural context (Coyle et al., 2010; Marsh and Lange, 2000).

\section{THE BENEFITS OF CLIL:}

In the CLIL approach, language has a vital role to play in teaching any subject. According to Marsh (2012), a fundamental rule in this educational approach is "using languages to learn and learning to use languages". Marsh (2012) noted that learning language is like learning a musical instrument; if the students do not practice it at home, they will not learn it as fully as they need to. Therefore, teaching subjects in the English language encourages learners to work and use it outside the classroom so they can gain a better understanding of the content of the subject matter. In doing so, they will learn English as they learn the content of the subjects.

According to Coyle et al. (2010), CLIL can provide opportunities for students to improve their English language skills in school and use those skills outside the classroom. Byrnes (2008) and Llinares et al. (2012) also demonstrated that CLIL classroom learners can develop and deal with everyday language and improve their ability to use English in daily communication. Hence, the essential aim of implementing the CLIL approach in the teaching process is to help learners create a better 
The Assassins: ancestors of modern Muslim suicide bombers?

Salam Abdulqadir Abdulrahman

environment in which they can use English outside the classroom so they can effectively use that language to communicate in their daily lives.

Moreover, most of the students in non-English speaking environments spend a lot of time focused on learning the English language without being able to use it after leaving school (Marsh, 2012). Consequently, CLIL gives learners opportunities to practice using English and it increases their confidence in their ability to use it in their future profession. Likewise, CLIL enhances the students' creativity and cognitive skills by teaching them how to learn a different language and gain content knowledge in that language (Baetens Beardsmore, 2008; Marsh, 2012; Coyle et al., 2010).

The CLIL approach can also help teachers solve the challenge of teaching subjects in a different language by using materials from those subjects. Deller and Price (2007) believed that courses using the CLIL approach have a more clearly defined syllabus/course outline and teachers will spend most of the time thinking about how to engage their students in learning rather than finding topics to study. They also mentioned another advantage of implementing the CLIL approach for young learners who started learning English earlier in their lives, because they do not need to repeat the same lessons when studying English in secondary school or high school (Deller and Price, 2007).

Harrop (2012) noted another important reason for implementing CLIL, which is keeping the language alive. For example, in the CLIL approach when a government decides to use English in its education system, it does not need to forget about the country's first language or the languages that are used by a majority of the people in that country. This approach also involves a key solution for bilingual and multilingual education contexts or for countries that have a solid opinion about people using other languages within their borders. In CLIL classes, when English is used as the main language in teaching and in the learning process, other languages are unlikely to disappear (2012).

CLIL takes into account that, in most bilingual and multilingual education contexts, students lack access to materials and resources written in their first language and other majority languages in all subjects (Fürstenberg and Kletzenbauer, 2012). Therefore, using the local language has an effect on an undeveloped education system and the lack of scientific research also makes teachers focus on only one course book and use one type of assessment method, which is administering an exam. However, in CLIL classes when the students learn the language within the context of subjects, they can engage in research to find more resources and stay up to date 413 with new information that is being published. In addition, CLIL can support learner autonomy by enabling students to find more information and by encouraging them to look for recent studies and current developments in their education area in the target language (almost always in English) because they do not have a problem with understanding the language in the materials they want to read (Benegas, 2012; Lasagabaster, 2009).

Motivation is one of the key factors of a successful teaching and learning process (Dornyei, 2001). Therefore, motivation is important as learning does not occur without it. Moreover, it can be difficult to improve learning without sufficient motivation. Most previous research studies that have examined CLIL have emphasised the need to increase a student's motivation to learn a language and integrate content (Banegas, 2012). Some of the students justified their weakness in learning English by pointing to their lack of interest in the irrelevant content that was used in their language lessons; so, CLIL can improve the students' motivation to learn the English language when it is used to teach relevant subjects (Harrop, 2012; Coyle and Holmes, 2009). Similarly, previous studies have reported that when students are comfortable with the content of the subjects and they have a positive attitude about their lessons, their schoolwork improves and they will be more successful (Coyle et al., 2010; Marsh 2002; Greenfell, 2002; Harrop, 2012).

\section{Methodology:}

This study was conducted online using an Internetbased questionnaire that targeted respondents from the limited Internet population (77 Kurdish students and teachers in the undergraduate and postgraduate levels). My background and own experience in the Kurdistan educational system motivated me to conduct this research in order to identify how to improve the Kurdish learners' ability to learn the English language. The semistructured interview method was also used as another research instrument to support the reliability of the results of the findings; as such, interviews were conducted with two Spanish students at Leeds Beckett University who had experience in the topic of this study in their home country. A mixed method approach (also called triangulation) has been selected as the methodology for this study in order to obtain qualitative and quantitative data. The purpose of using this approach is to take advantage of using the strengths offered by compiling both quantitative and qualitative data. 


\section{FINDINGS AND DISCUSSION:}

The study set out with the aim of assessing the importance of using English in teaching some of the main subjects in the Kurdistan education system. The collected data highlighted the main difficulties that students face in school and when they attend university. The study will discuss to present detailed suggestions to tackle these outstanding issues.

\section{A. Why CLIL is useful for Kurdistan education system:}

In terms of the main language used in teaching and learning, this study suggests the need for changes in the Kurdistan educational system. The first two questions in the questionnaire sought to determine the difference between which main language is used in the teaching process in schools and universities in Kurdistan. As results show, Kurdish language as the first language of the most of the people in Kurdistan was used as the main language in learning and teaching process in schools with the average of $74 \%$, however, the use of Kurdish in the university level dropped to average of $13 \%$. On the other hand, the average of using English language as the main language in Kurdistan's schools was $5 \%$, nevertheless, it increased to average of $71 \%$ in the university level. This gap between primary education and higher education levels may have a negative impact on students' progress and their ability to learn content. Students in higher education may also find it difficult to learn English without gaining a base proficiency at the primary education level (participants A and B) (Marsh, 2010, Benegas 2012; Lasagabaster 2009; and Coyle et al. 2010).

The results of this study show that CLIL can be a key for improving teaching quality. Most of the participants thought that teaching science and math in English will increase teaching quality in Kurdistan schools. The results show that $82 \%$ of the respondents felt that studying other subjects in English language motivates them to learn the language. Also, $68 \%$ of the respondents consider that studying other subjects in English language encourages them to learn independently, however, $23 \%$ of them were not sure. Results have shown that CLIL can increase teachers' ability to impart knowledge to students because teachers studied their subjects in university in English and thus will be more successful at teaching the curriculum in the same language.

The most interesting finding was that that most of the participants believe that English language classes in school are not enough to gain proficiency. Totally, \%84 has shown their agreement with that only English language lesson in schools is not enough to learn this language. Marsh (2010) argues that CLIL can provide opportunities for students to learn English through content of other subjects and they will be able to use it after graduating. Moreover, the qualitative data reported the impact of studying other subjects in English to provide more opportunity to the students to use the language to do their work and communicate outside the classroom (participants A and B).

One of the most important relevant finding in support of implementing the CLIL approach in Kurdistan education system was the large proportion of the participants (\%79) who expressed that they have faced problems because of the lack of ability to use English language when they attend university. Moreover, nearly the same proportion stated that they have difficulty finding sufficient academic resources in science subjects in their mother tongue (Kurdish) to do research reports (Byrnes, 2008; Llinares et al. 2012; Deller \& Price, 2007; Benegas, 2012; and Lasagabaster, 2009).

\section{B. Teachers' and students' perspective on CLIL:}

Using English as one of the main languages in the teaching process can lead to better collaboration to gain language proficiency. In this study, $\% 79$ of the respondents showed satisfaction with the teaching content of some of the main subjects in English. Consequently, nearly the same proportion of them thought studying lesson content in English would raise their interest in learning more about the English language, conversely, $23 \%$ of the respondents answered with "No". Similarly, the results show that respondents found English classes/lectures to be more interesting than the classes and lectures which were in Kurdish or Arabic, and most of the reasons which were given were about seeking to learn English. However, \%30 of the respondents who were not interested in English classes and lectures thought that studying in English made the subject difficult to understand. Furthermore, some said holding courses in English would not make a class or lecture interesting (Mehisto et al. 2008; Deller \& Price, 2007).

The highest proportion of respondents in this study, which was $\% 92$ of the respondents, states the reason for their learning English is to use it in a future profession. Moreover, the results show that Kurdish students and teachers strongly believe that learning English will improve the academic level of universities in Kurdistan. Similarly, both points were confirmed by the two Spanish respondents who had study experience in CLIL. The Spanish respondents stated they felt more comfortable using English at the undergraduate and 
The Assassins: ancestors of modern Muslim suicide bombers?

Salam Abdulqadir Abdulrahman

postgraduate levels. As a result, they also felt confident to apply for any job that requires English proficiency (Baetens \& Beardsmore, 2008; Marsh, 2012; Coyle et al. 2010).

The results show that studying other subjects in the English language motivates students to learn and encourages them to learn independently (Banegas, 2012; Dornyei, 2001; Harrop, 2012; Coyle \& Holmes, 2009). The average of respondents reached $82 \%$ who felt that studying other subjects in English language motivates them to learn the language, and $68 \%$ of them consider that studying other subjects in English language encourages them to learn independently. Although, in terms of relationship between culture and language, this study found that studying the content of subjects in English raises students' interest to learn more about British and other international cultures (Coyle et al. 2010; Marsh \& Lange, 2000). Learning about the culture of those countries does not mean students want to change their culture; however, it does allow them to communicate with an international audience (Kramsch, 2006). On the other hand, Coyle et al. (2010) indicated that in some countries such as Germany, France and Australia, CLIL was used to study other languages, not only English, in the same way. Therefore, as Harrop (2012) pointed out, CLIL keeps a language and culture alive while presenting an alternative strategy for learning a target language.

\section{Implementing CLIL in Kurdistan education system:}

About half of the respondents have chosen all the topics of science and math subjects to be taught in English and a quarter of them want most of the topics of those subjects be taught in English. However, one of the unanticipated findings was that a high proportion of respondents did not agree with history and geography to be taught in English. The average of participants who refused to study/teach science subjects and mathematics in English was between $13 \%$ and $16 \%$ but for both Geography and History subjects was between $34 \%$ and $39 \%$. A possible reason for this might be English is not used as a main language for teaching in history and geography departments in the Kurdistan higher education system (Jukil, 2009). However, the results show that $74 \%$ of the respondents believe that science subjects such as Chemistry, Physics, Biology, and Mathematics should be taught in English. Also, 69\% of the responses agreed that teaching content of those subjects in English in Kurdistan schools will improve teaching quality because teachers studied their subjects in university in English and most of the participants agreed with the statement that teaching science subjects and mathematics in English in Kurdistan schools will help students to be successful at university level.

415
Both Spanish respondents who were interviewed gave similar reasons for studying some of the main subjects in English to those by most other respondents, who said science and math subjects should be taught in English. Additionally, those factors which support the implementation of CLIL, such as the importance of learning English as a global language and more updated available resources are written in that language were reported by Marsh (2012), Coyle (2007) and Martinez (2013).

As what the both Spanish respondents stated is similar to the results of the quantitative data which shows the importance of learning English from early age. Moreover, as previous research investigated, students in CLIL classes need to have a base in English to start studying other subjects in that language (Lee \& Jeong, 2013; Martinez, 2013; Coyle, 2007). Simultaneously, if the English lessons were only about itself, it could result in students losing interest in English (Marsh, 2012). Therefore, CLIL can offer a different environment to learn English through the study of some core curriculum content (Llinares et al. 2012; Byrnes, 2008).

The results showed that \%93 of the participants preferred to change assessment methods in Kurdistan education system, and that writing assignments and reports, presentations, posters and research to be used instead of traditional written exams (Sharif, 2013; Jukil, 2009). Likewise, it is reported in this study that studying main subjects in English improves learners' ability to improve their language skills and will help students to access more up-to-date resources to undertake diverse assessments (participants A and B). Therefore, implementing CLIL in Kurdistan education system requires not only changing the instructional language in some of the main subjects to English, but also to improve the teaching quality, academic level, effective transfer of information and knowledge to students.

\section{CONCLUSION:}

The purpose of the current study was to determine the impact of implementing the Content and Language Integrated Learning (CLIL) approach in Kurdistan education system. This study investigated teachers' and students' perceptions in the effect of teaching content of some of the main subjects in Kurdistan schools in English on raising teaching quality and meeting students' needs in language learning for their future academic studies and professional careers. Returning to the reasons posed at the beginning of this study, it is now possible to state that CLIL can help to improve learners' ability to use English and the academic level of schools and universities in Kurdistan. 
The relevance of learning English in Kurdistan schools is clearly supported by the current findings. One of the major finding of this study was that studying only English language lessons in schools is not enough to become proficient in the language. This study has shown that implementing CLIL in Kurdistan education system offers more opportunity for the students to improve their English language skills through communication and doing work outside of the classroom. The results also showed teachers and students in Kurdistan educational system preferred studying the content of some of the main subjects such as physics, chemistry, biology and mathematics in English.

The most obvious finding to emerge from this study is that teachers and students were feeling confused because of this gap between education level and higher education level in using different languages as a main language of teaching, especially in science departments at all the universities that only use English. The study reported that using English as a main language in teaching science and mathematics subjects allows students to find up-to-date resources that were otherwise difficult to find in their native language.

The results of this study support the idea that learning English at an early age is important for the educational advancement of children in Kurdistan. However, these findings suggest that starting with learning basic English at early age is needed to implement the CLIL approach successfully and to reach its goals to develop Kurdish learners' ability to use English through seeking to provide more opportunity and creating different academic environment. Moreover, the study suggests that students are not interested in studying English itself for a long time. Therefore, instead of teaching English itself for 12 years (from the first year of primary school until the last year of high school) Kurdistan education system can take a different strategy for learning English by implementing CLIL.

The results of this study indicate that CLIL could progress learners' English language skills, such as reading, listening, writing, speaking, while improving their ability to access research and academic resources in English without problems in understanding. The evidence in this study indicates that while using English in teaching science subjects and mathematics in Kurdistan's schools, the educational system might simultaneously apply a variety of assessment methods in place of written exams, such as writing assignments or/and reports, posters, presentations and research projects.

Although the current study is based on a small sample 416 of participants (77 people) who are studying or teaching in Kurdistan's schools and universities, the findings, which are supported by reviewed literature, suggest that implementing a CLIL approach would bring essential advantages to the teaching and learning process in Kurdistan education system. As the first study about CLIL in Kurdish context, the current findings add to a growing body of literature on teaching English through the content of some of mains subjects in schools in Kurdistan education system. Hence, the findings and methods used for this study may be applied to other studies in different contexts in the Middle East and North Africa (MENA).

Finally, the study has successfully demonstrated the importance of implementing CLIL in Kurdistan's schools and its goal to develop Kurdish learners' ability to use English through seeking to provide more opportunity and creating different academic environment. Similarly, it has examined the advantages of CLIL in improving teaching quality and academic level and its impact on supporting students in their future academic studies and professional careers. However, it has certain limitations in terms of how to deal with large class sizes, how to develop teacher and staff ability to work in CLIL classes, who should write and choose the materials to be used in CLIL classes, and how the use of technology will influence teaching and learning in CLIL classes.

\section{RECOMMENDATION}

The findings of this study have a number of important implications for future practice and it has raised many questions for further investigation. It is recommended that further research be undertaken in the following areas:

1. Reforming Kurdistan education is one of the important changes which needs to be made, especially in using languages in teaching and has to indicate its aims in learning those languages.

2. Classroom research is needed to determine the shortcomings of the methods that are currently used in teaching English lessons in Kurdistan's public schools and to assess and illustrate how ineffective their methods have been in improving students' English language proficiency.

3. More research is needed to examine more closely the links between the impact of implementing CLIL in Kurdistan's schools and how CLIL can be improved in the Kurdish context. 
The Assassins: ancestors of modern Muslim suicide bombers?

Salam Abdulqadir Abdulrahman

4. Another possible area of future research would be to evaluate current English textbooks, hours of teaching and the time that is set for each skill in English per week.

5. Further research in the field of improving teaching quality would be of great help in classroom observation and improving feedback for English lessons in Kurdistan's schools.

\section{REFERENCES}

[1] BANEGAS, D.L., 2012. Motivation and autonomy through CLIL. A collaborative undertaking. Views on Motivation and Autonomy in ELT: Selected Papers from the XXXVII FAAPI Conference 2012, pp. 39

[2] BYRNES, H. (2008). Assessing content and language. E. Shohamy (Ed.), volume 7: Language testing and assessment. New York: Springer, pp. 37-52.

[3] COYLE, D., 2007. Content and language integrated learning: Towards a connected research agenda for CLIL pedagogies. International Journal of Bilingual Education and Bilingualism, 10(5), pp. 543-562.

[4] COYLE, D., HOLMES, B. and KING, L., 2009. Towards an integrated curriculum: CLIL national statement and guidelines. London: The Languages Company.

[5] COYLE, D., HOOD, P. and MARSH, D., 2010. CLIL: Content and language integrated learning. Cambridge: Ernst Klett Sprachen.

[6] DALMA, J., 2013. Team-teaching a type of cooperation between native and non-native teachers in Hungarian Primary CLIL programmes. In: ÁRVA, V., MÁRKUS, É, ed, Education and/und Forschung. Budapest: ELTE TÓK Tudományos Közlemények XXXV, pp. 60-77.

[7] DALTON-PUFFER, C., NIKULA, T. and SMIT, U., 2010. Charting policies, premises and research on content and language integrated learning. In: C. DALTON-PUFFER, T. NIKULA and U. SMIT, eds, Language Use and Language Learning in CLIL Classrooms. Amsterdam: John Benjamins Publishing, pp. 1-19.

[8] DELLER, S. and PRICE, C., 2007. Teaching Other Subjects Through English. Oxford: Oxford University Press Oxford.

[9] DORNYEI, Z., 2001. Motivational Strategies in the Language Classroom. Cambridge: Cambridge University Press.

[10] FÜRSTENBERG, U. and KLETZENBAUER, P., 2012. CLIL: from Online Sources to Learning Resources. ICT for Language Learning, .

[11] GAJO, L., 2007. Linguistic knowledge and Subject knowledge: how does bilingualism contribute to subject develompent? International Journal of Bilingual Education and Bilingualism, 10(5), pp. 563-581.

[12] GREENFELL, M., ed, 2002. Modern Languages across the curriculum. London: Routledge.

[13] HARROP, E., 2012. Content and Language Integrated Learning (CLIL): limitations and possibilities. Encuentro, 21, pp. 57-70.

[14] JUKIL, A.M., 2009. The policy of educational system in IraqKurdistan. Erbil: Salahaddin University.

[15] KRAMSCH, C., 2006. Culture in Language Teaching. In: H.L. ANDERSEN, K. LUND and K. RISAGER, eds, Culture in Language Learning. Lancaster: Aarhus university press, pp. 1125 .

[16] LASAGABASTER, D., 2009. Language attitudes in CLIL and traditional EFL classes. International CLIL Research Journal, 1(2), pp. 4-16.

[17] LEE, J.S. and JEONG, E., 2013. Korean-English dual language immersion: perspectives of students, parents and teachers. Language, Culture and Curriculum, 26(1), pp. 89-107.

[18] LLINARES, A., MORTON, T. and WHITTAKER, R., 2012. The Roles of Language in CLIL. Cambridge: Cambridge University Press.
[19] MARSH, D., 2012. Content and Language Integrated Learning (CLIL) A Development Trajectory. Córdoba: University of Córdoba.

[20] MARSH, D., 2000. An introduction to CLIL for parents and young people. In: D. MARSH and G. LANGÉ, eds, Using Languages to Learn and Learning to Use Languages. Jyväskylä: University of Jyväskylä, .

[21] MARSH, D. and LANGÉ, G., 2000. Using languages to learn and learning to use languages. Finland: University of Jyväskylä.

[22] MARTINEZ, S.H., 2013. CLIL: The application of this innovative educational approach in different European countries, Universidad de Oviedo.

[23] MEHISTO, P., FRIGOLS, M.J. and MARSH, D., 2008. Uncovering CLIL: Content and Language Integrated Learning and Multilingual Education. Oxford: Macmillan.

[24] SHARIF, T., 2013. Importing Educational Services from Finland to Kurdistan. Helsinki: Haaga-Helia University of Applied Sciences. 